\title{
Procesos criminales a instancia de parte privada. Apuntes sobre su praxis en el Real Consell Criminal valenciano en época de Felipe II
}

\section{Criminal proceedings at the request of a private party. Notes on its praxis in the Real Consell Criminal valenciano during the time of Felipe II}

\author{
María-Dolores HernándeZ-FernándeZ \\ maria.d.hernandez@uv.es
}

id.orcid.org/0000-0003-4443-3062

Universitat de València

\begin{abstract}
Resumen: El presente trabajo indaga sobre las posibilidades de conocer el proceso criminal valenciano a través del estudio de los procesos instados por particulares ante el Real Consell Criminal de la Real Audiencia valenciana. El estudio de la praxis de la justicia del rey en el Real Consell Criminal puede aportar datos interesantes, más allá del conocimiento del proceso criminal valenciano o del funcionamiento de la justicia de la Real Audiencia, también sobre el funcionamiento de la justicia criminal en el Antiguo Régimen en general.
\end{abstract}

Palabras clave: Real Consell criminal, proceso criminal, demanda, avocación, sagraments

\begin{abstract}
The present work explores the possibilities of knowing the valencian criminal process through the study of processes urged by individuals on the Real Consell Criminal of the Real Audiencia valenciana. The study of the justice praxis of the king in the Real Consell Criminal can provide interesting data, beyond the knowledge of the Valencian criminal process or the functioning of the justice of the Real Audiencia, also on the operation of criminal justice in the Old Order in general.
\end{abstract}

Keywords: Real Consell criminal, criminal process, demand, avocación, sagraments

\footnotetext{
* Becaria del Programa VALI+d para Personal Investigador en Formación de Carácter Predoctoral ACIF/2016/332 de la Conselleria d'Educació, Investigació, Cultura i Esport, Direcció General d'Universitat, Investigació i Ciència, actividad cofinanciada por el Fondo Europeo de Desarrollo Regional (FEDER). Trabajo realizado en el marco del proyecto HAR2014-53298-C2-1, «Nuevas perspectivas de Historia Social en los territorios hispánicos del Mediterráneo Occidental en la Edad Moderna», financiado por el Ministerio de Economía y Competitividad.
} 
María Dolores Hernández-Fernández. Procesos criminales a instancia de parte privada. Apuntes sobre su praxis en el Real Consell Criminal valenciano en época de Felipe II

\section{Introducción}

Durante la Edad Moderna se aprecia una creciente implicación de los emergentes poderes estatales en la tarea de contener la criminalidad bajo niveles soportables para la convivencia. Una de las medidas adoptadas fue la criminalización de las conductas más lesivas a través del derecho, el uso del llamado ius puniendi. Una vía formalizada que, a diferencia de otras instancias de satisfacción de conflictos, solo permite una solución previamente prescrita que consiste en el sacrificio de los intereses de una parte en beneficio de la otra (Hassemer y Muñoz 2012). Pero también es constatable, junto al aumento progresivo del ius puniendi, el crecimiento y fortalecimiento de aparatos judiciales reales adecuados para conocer la cada vez más compleja realidad criminal, en la que convergen los nuevos supuestos ilícitos con un continuo aumento de la conflictividad interpersonal. Ésta es una línea de investigación, iniciada por Tomas y Valiente (1969) y Alonso Romero (1982), que defiende la existencia de un proceso paralelo entre la formación del Estado moderno y la imposición de la autoridad monárquica mediante la intensificación del ius puniendi y el fortalecimiento del aparato judicial real. Estos autores sostienen que el uso del proceso y la ley penal fue uno de los medios más importantes para el afianzamiento del poder del rey, en el que la implantación paulatina del procedimiento criminal inquisitivo en los tribunales bajo control real se puede considerar como un arma autoritaria y de intimidación.

Pero la imposición de la autoridad monárquica fue un proceso lento, históricamente apreciable cuando se verifica la convivencia entre el fortalecimiento del aparato judicial real y la pervivencia de otras formas tradicionales de solución de conflictos: la existencia de delitos privados perseguibles solo a instancia de la parte agraviada mediante la acusación, la persistencia de la venganza personal, los duelos por honor y otros llamados escapes sociales. De este modo, el aumento de la coerción se va percibiendo como un fenómeno superpuesto a la realidad judicial medieval, en la que primaba el sistema acusatorio, sobre el que se va articulando lentamente el sistema inquisitivo (Mantecón 1996). En los reinos hispanos esta labor es iniciada por los Reyes Católicos y continuada por los Austrias que, preocupados por el fortalecimiento del poder del rey, la pacificación de sus reinos, el sometimiento de la nobleza y la política de unidad religiosa, crean y fortalecen el aparato institucional de la justicia real para conseguir estos fines (Tomás 1969).

\section{Los procesos criminales conservados de la Real Audiencia del Reino de Valencia. Una cuestión de oportunidad.}

En este contexto de fortalecimiento del aparato judicial real hispano se sitúa la fundación, por Fernando II, de la Real Audiencia del Reino de Valencia (Canet 1986) mediante la Pragmática de Valencia de 30 de agosto de $1506 .{ }^{1}$ Completada, a suplicación de la ciudad de Valencia, por la Pragmática de la Real Audiencia fechada en Burgos el 30 de noviembre de 1507. Incluida entre los

1 Transcrita por Canet (1986: 193-196).

SCRIPTA, Revista internacional de literatura i cultura medieval i moderna, núm. 13 / juny 2019 / pp. 113 - 138 ISSN: 2340-4841 · doi:10.7203/SCRIPTA.13.15477 
María Dolores Hernández-Fernández. Procesos criminales a instancia de parte privada. Apuntes sobre su praxis en el Real Consell Criminal valenciano en época de Felipe II

privilegios de Fernando II en el Aureum Opus, en este documento, el Católico justifica la creación de la Audiencia dado que "...volents nós, ab suma vigilància, entendre en lo redreç y administració de la iustícia en la nostra ciutat y regne de València...", así “...estatuïm e ordenam ab nostra pracmàtica sanctió oportunament expedida (...) que en lo dit regne hagués consell e audiència real ordinàriament...". ${ }^{2}$ Decisión apremiada por el absentismo regio con la que se dotaba, además, de un órgano asesor al virrey y que supuso el reforzamiento de las instituciones que tenían por objeto hacer presente al rey en el reino (Canet 1986).

En consecuencia, es presumible pensar que la Real Audiencia valenciana, como Cort Reial que era, se convirtiese de entre las instancias con jurisdicción en materia criminal, en el órgano ejecutor más adecuado para llevar a cabo un previsible afianzamiento del poder del rey mediante el control de las cuestiones relacionadas con la justicia y el orden público. Pero, en un análisis sobre este tema, no podemos dejar de tener presente que la Real Audiencia tuvo que acomodar su funcionamiento al sistema institucional y normativo foral valenciano en el que había quedado incorporada. El sistema foral contaba ya con tres siglos de existencia, un ordenamiento positivado a través de la aportación sucesiva de furs, actes de cort y privilegios dados en distintas Cortes desde el siglo XIII, pero también de pragmáticas. Normativa con carácter acumulativo y vigencia secular como toda la legislación del Antiguo Régimen (Peset 1995: 15). Prueba de las dificultades de su encaje en el reino es la formalización de grenges por los brazos, en las Cortes del XVI y XVII, sobre cuestiones relacionadas con el respeto a los furs en su actuación y, también, no pocas contenciones de jurisdicción con el resto de instituciones regnícolas preexistentes con competencia criminal (Canet 2002).

En el contexto de la investigación sobre la dimensión histórica de la justicia criminal en Época Moderna, el estudio de la praxis de la justicia del rey en la Real Audiencia valenciana puede aportar datos interesantes, más allá del conocimiento del procesamiento criminal en la Valencia foral o del funcionamiento de la justicia de la Real Audiencia, también sobre la justicia criminal en el Antiguo Régimen en general. Especialmente si tenemos en cuenta que se conserva en el Archivo del Reino de Valencia (ARV) y la sección Real Audiencia que contiene una rica documentación administrativa y procesal procedente de causas criminales sustanciadas ante la citada institución entre los siglos XVI y XVII.

Existen inventariados aproximadamente 6.000 documentos descritos como procesos criminales, además de otra ingente cantidad de documentación relacionada con la justicia criminal en otras secciones del ARV. Esta circunstancia plantea una gran diferencia con lo sucedido con la documentación procesal criminal de otras instituciones forales valencianas de las que se conserva escasa documentación (Pérez 1991). Pero también en relación con lo sucedido en otros órganos jurisdiccionales de la Monarquía Hispánica, por ejemplo, con la documentación de la Sala de Alcaldes de Casa y Corte radicada en Madrid desde 1561, de la cual han desaparecido los Libros de Acuerdos de la Sala y las causas criminales anteriores a 1700 (Llanes 2013); o de la Real Audiencia de Cerdeña,

2 Privilegia XXXVI, Pragmática de la Real Audiencia, Ferdinandi Secundi, ff. CCXXXII-CCXXXIII.

SCRIPTA, Revista internacional de literatura i cultura medieval i moderna, núm. 13 / juny 2019 / pp. 113 - 138 ISSN: 2340-4841 $\cdot$ doi:10.7203/SCRIPTA.13.15477 
María Dolores Hernández-Fernández. Procesos criminales a instancia de parte privada. Apuntes sobre su praxis en el Real Consell Criminal valenciano en época de Felipe II

donde solo se conservan unas tres decenas escasas de procesos, muy incompletos, procedentes de los siglos XVI y XVII. ${ }^{3}$ Por lo que estamos ante una de las pocas oportunidades en la que se puede intentar una aproximación a la realidad cotidiana de la justicia criminal en Época Moderna a través del estudio directo de los procesos.

Conocer el modo en el que sustanciaban las causas criminales por el alto tribunal, es un paso previo necesario, en primer lugar, para estar en mejor disposición para acometer el análisis de la ingente cantidad de documentación judicial conservada emitida por la Real Audiencia. En segundo lugar, para dilucidar una posible especificidad procesal criminal de lo actuado ante la Real Audiencia valenciana en el contexto jurisdiccional regnícola. ${ }^{4} \mathrm{Y}$, por último, para poder avanzar en el estudio de los paradigmas a que hemos hecho referencia anteriormente para el Reino de Valencia: el uso del ius puniendi por el poder real mediante la creación de nuevos ilícitos y la reserva o no del conocimiento de los mismo a los tribunales reales; o la posible función del proceso criminal como instrumento de gobierno, dilucidando la naturaleza del proceso valenciano, acusatorio o inquisitivo.

Pero cuando se estudia una institución jurídica hay que tener en cuenta el tiempo histórico en el que vamos a valorarla, ya que las normas por las que se rigen van cambiando por su discurrir y la coyuntura, además, no siendo su evolución en el mismo sentido. Por lo que es necesario acotar temporalmente. Hay distintas formas de abordar esta cuestión diacrónica y una de ellas puede ser situarse en un momento clave de la vida de la institución para después analizar los antecedentes y la evolución posterior. Varias circunstancias apoyan la opción del reinado de Felipe II, en concreto las décadas comprendidas entre 1560 y 1570, como punto de partida más adecuado para el estudio del proceso criminal en la Real Audiencia valenciana. La primera es de tipo práctico, una parte muy importante del grueso de la documentación criminal conservada en el ARV de la Real Audiencia pertenece al reinado de Felipe II, lo que facilita el necesario contraste entre lo regulado en la normativa regnícola y lo actuado por el tribunal. En segundo lugar, porque en este momento se produce el "viraje filipino", término acuñado por Reglà (Canet 1986: 39 y 2006), con un salto cualitativo en la preocupación del rey por graves problemas que estaban haciéndose crónicos, especialmente, en materia de orden público: las bandosidades (Catalá 1996 y 1999), el bandolerismo, la piratería y el control de los moriscos (García 1977; Catalá y Urzainqui 2010 y 2016). En los trabajos de los autores citados se trasluce un aumento del número de causas criminales sobre estas cuestiones en el en las décadas centrales del reinado. Y, por último, y no menos importante, porque en este periodo coinciden el momento de madurez institucional de la Monarquía Hispánica y de consolidación de la Real Audiencia con la creación de la Sala Criminal, el Real Consell Criminal.

3 Archivio di Stato di Cagliari (ASCA), Antico Archivio Regio, Miscellanea, bustas 211 a 213.

4 Respecto al resto de instituciones nos remitimos, entre otros, a los trabajos de Salvador (1984) sobre los la Gobernación General y sobre las Lugartenencias a Bernabé (2014); para la bailía a Piles (1970); para el justicia criminal de la ciudad de Valencia a los trabajos de Pérez (1991), y entre otros, sobre la justicia señorial a los trabajos de Febrer (1996), Bernabé (1993 y 2010), Ciscar (2009) o Hernández Ruano (2014). 
María Dolores Hernández-Fernández. Procesos criminales a instancia de parte privada. Apuntes sobre su praxis en el Real Consell Criminal valenciano en época de Felipe II

\section{Disposiciones normativas de los años centrales del siglo XVI}

Ya en el último tercio del reinado de Carlos I se percibe un aumento de la carga de trabajo de la Real Audiencia que devino en graves problemas de eficacia, dando lugar a importantes reformas en la institución (Canet 2001). En la misma dirección, Felipe II es consciente de la necesidad de seguir realizando reformas y una de las primeras será establecer una sala específica para conocer de asuntos criminales. Así, como primer paso, dicta la Nova Pragmatica Regiae Audientiae, de 2 de junio de 1560, donde se instituyen dos plazas de jutges de cort con dedicación exclusiva en materia criminal (Canet 1986: 34-90). Posteriormente en las Cortes de 1564, primeras de su reinado y a súplica de los tres estamentos, se crea el Real Consell Criminal. ${ }^{5}$ De este modo queda corroborada por vía de fur la separación del conocimiento de las causas civiles y criminales en distintas salas en la Audiencia, lo que presumiblemente redundó positivamente en la eficacia en materia criminal. Las reformas no acabaron ahí y la voluntad del prudente de continuarlas quedó patente cuando se reservó en la sanción del fur XXVIII (que estableció la división en dos salas) “.... millor delliberació, sa magestat provehir a lo que convé, ab què lo que 's conté, axí en aquest capítol com en tots los altres que tractaran de l'orde del civil y criminal, salaris y orde de la administració de la justícia...”. Así, se dicta el 1 de mayo de 1564 una Provisión real sobre la composición del Real Consell Criminal y el salario de sus miembros, disposición que completa lo establecido en las Cortes ampliando a tres, los jutges de cort que han de despachar los asuntos criminales junto con el abogado fiscal y el regente de la cancillería. ${ }^{6} \mathrm{Y}$ la Real Pragmàtica sobre los salaris dels Procuradors Fiscals de 5 de febrero de $1565^{7}$ que establece los salarios de los procesos de estos oficiales en función, fundamentalmente, de la pena establecida en sentencia, pero estableciendo también los salarios en los casos de remissió o perdó, incluso en caso de lletres inbibint al jutge secular.

Reformas que se prolongarán hasta las Cortes de 1585, mediante esta vía de la promulgación de pragmáticas, ordinacions y provisiones reales dirigidas, fundamentalmente a regular la institución, ${ }^{8}$ pero que también incluyen importantes disposiciones con contenido procesal criminal. Las más importantes en este sentido son: Pragmàtica de la Magestat del Rey Don Phelip primer, dada en Setaygues, a 25 de Abril del any 1564; Ordinacions fetes per Don Joan Llorens de Vilarrasa, a 27 de Nohembre 1566; Del orde de la publicació de les Sentencies Reals, y execució de aquelles, y de la guarda dels Alguazirs en lo Real Palacio, fet per lo Conte de Benavent en lo any de 1568 y Ordinacions de Vespasiano Gonzaga de 24 de juliol de 1577. Estas últimas disposiciones estan incluidas en una recopilación impresa en 1608, cuarenta

\footnotetext{
5 Furs, Capitols, Provisions, e Actes de Cort, fets y atorgats per la S.C.R.M. del Rey don Phelip nostre senyor ara gloriosament regnant en les Corts generals per aquell celebrades als regnicols de la ciutaty regne de Valencia, en la vila de Monco, en lo any MDLXIIII, València, MDLXV (Cortes de 1564) Fur, Capítulo (Cap.), XXVIII, ff. IIII v. y V r. (Edición facsímil a cargo de Salvador (1974).

6 Transcrita por Canet (1986: 202-203).

7 ARV, Real Cancillería (RC), 601, ff. $271 \mathrm{r}^{\circ}-274 \mathrm{r}^{\circ}$

8 Para una completa visión de las importantes modificaciones institucionales en la Real Audiencia hay que remitirse a los trabajos de Canet (1986: 41-75; 2001, 2002; 2010)
}

SCRIPTA, Revista internacional de literatura i cultura medieval i moderna, núm. 13 / juny 2019 / pp. 113 - 138 ISSN: $2340-4841 \cdot$ doi:10.7203/SCRIPTA.13.15477 
María Dolores Hernández-Fernández. Procesos criminales a instancia de parte privada. Apuntes sobre su praxis en el Real Consell Criminal valenciano en época de Felipe II

años después, mandada hacer por el virrey Luis Carrillo de Toledo, marqués de Caracena, junto con disposiciones anteriores: Pragmàtica de la institució de la Real Audiència feta per la Cesarea Magestat del Emperador Carlos Quinto en Barcelona lo primer de Maig 1543; Ordinacions fetes per lo Duch de Maqueda, a 11 de Janer de 1556; Provisió del Duch de Maqueda a 29 de Maig 1559; Orde del Duch de Sogorb de 3 de Nohembre 1559. En el preámbulo de dicha recopilación se indica que en ella se contienen las pragmáticas, ordinacions y provisiones reales que se tenían que leer el segundo día de enero de todos los años para que los doctores de la Real Audiencia, escrivans de manament, procuradors fiscals, alguazirs, escrivans, verguers, porters y los demás ministros supieran qué debían hacer y en qué se debían abstener. ${ }^{9}$ Esto nos da idea de la importancia que estas disposiciones de los años centrales del siglo XVI tuvieron en la ordenación procesal criminal en la Real Audiencia en los años siguientes.

\section{La avocación de causas ante el Real Consell criminal}

La existencia misma de la posibilidad de conocer el Real Consell Criminal en primera instancia procesos criminales parece contradecir prima facie lo regulado en furs. Desde Jaime I se estableció que la capacidad para juzgar los crímenes era otorgada a un sol vebi, ${ }^{10}$ el justícia, elegido según los procedimientos previstos foralmente, institución que pervivió durante todo el periodo foral (Graullera 1997 y Pérez 1991 y 2013). Obarrio (1994) al tratar el tema de la naturaleza del proceso criminal valenciano, acusatorio o inquisitivo, a la luz del ius commune y los comentaristas, en un análisis teórico basado fundamentalmente en la regulación foral medieval, señala que a la vista de lo regulado por furs en el proceso criminal valenciano la actividad del procurador fiscal real estaba sometida a un severo control por parte de la legislación foral, lo que dificultaba su intervención de oficio como parte actora en procesos criminales, por lo que estima que este tipo de causas eran promovidas mayoritariamente por los particulares y conocidas por sus jueces naturales, los justicias, ya que los furs establecen que no se puede procesar si no había formulada acusación formal por parte del perjudicado por el delito mediante clam; es decir, cuando la parte ofendida pide al juez ordinario que inste un procedimiento para que castigue el delito cometido por una persona concreta. En consecuencia, este autor plantea la hipótesis de que la norma general, según los furs, es que todos los crímenes son privados y solo pueden ser perseguidos a instancia del agraviado ante los justícies, los ordinarios (Obarrio 1994: 65-67). ${ }^{11}$ Considera, por tanto, la existencia de procesos iniciados de oficio por el procurador fiscal real muy escasa a causa de las constricciones forales.

Sin embargo, el grueso de la documentación procesal criminal del Real Consell Criminal inventariada en el ARV procede de procesos sustanciados en primera instancia ante este tribunal, que en principio

\footnotetext{
9 ARV, RC, 601, ff. $151 \mathrm{r}^{\circ}-168 \mathrm{v}^{\circ}$.

10 FRV, libro I, rúbrica III, fur XVIII.

11 Queda planteado en el mismo sentido por Pérez (2013).
}

SCRIPTA, Revista internacional de literatura i cultura medieval i moderna, núm. 13 / juny 2019 / pp. 113 - 138 ISSN: 2340-4841 $\cdot$ doi:10.7203/SCRIPTA.13.15477 
María Dolores Hernández-Fernández. Procesos criminales a instancia de parte privada. Apuntes sobre su praxis en el Real Consell Criminal valenciano en época de Felipe II

no es juez ordinario para este tipo de causas. Documentación conservada que suponemos se trata, además, de una pequeña parte de lo realmente actuado, a tenor de las referencias a cientos de otras causas criminales en primera instancia en los libros registro de Real Cancillería, Real Audiencia o Mestre Racional. Circunstancia que puede hacernos considerar un cambio en la escena jurisdiccional criminal desde la irrupción de la Real Audiencia en el panorama regnícola. ${ }^{12}$

En orden a poder explicar la existencia de estas causas criminales sustanciadas en primera instancia por la Real Audiencia, hay que tener en cuenta que éste se fundó como el más alto tribunal en Valencia con jurisdicción ilimitada, en teoría, de carácter ordinario y por tanto también con posibilidad de conocer en primera instancia cualquier causa criminal, siempre y cuando estas fuesen avocadas a la Real Audiencia, como consta en la Pragmática de creación de la Real Audiencia de 30 de agosto de 1506 (Canet 1986: 118 y 193). La muestra de que el número de causas avocadas fue aumentando es el hecho de que esta potestad ilimitada tuvo que ser acotada para los particulares, en principio para no restar capacidad de actuación y eficacia en la sustanciación de causas de mayor interés para la gobernanza del reino. Felipe II estableció limitaciones por razón de la materia mediante la Pragmàtica real pera que nos puguen tractar en la Real Audiència causes algunes criminals en primera instancia, sinó les de pena de mort, mutilació de menbre, o de altra gran pena corporal, de 23 de marzo de 1564 elevada en las Cortes de 1585 a fur. Con ella se reducía la capacidad de avocación al Real Consell Criminal solo de los crímenes castigados con las más graves penas corporales. ${ }^{13} \mathrm{La}$ otra limitación fue por razón de la distancia, por los gastos que se ocasionaban a los particulares la sustanciación de causas pertenecientes al ámbito territorial de las gobernaciones. La limitación de las causas de la gobernación de Orihuela ya fue establecida en tiempos de Carlos I en las Cortes de 1542, ${ }^{14}$ las de la gobernación de Játiva en las Cortes de 1564 y en las Cortes de 1604 las causas de la gobernación de Castellón de la Plana, extendida también a los justicias de las villas reales. ${ }^{15}$ Sobre la efectividad de estas medidas, Matheu comenta, que las limitaciones de avocación a que hemos hecho referencia, aún en la segunda mitad del siglo XVII, solo operaban cuando la causa era iniciada por la parte en primer lugar ante el juez ordinario competente y, por el contrario,

12 Por ejemplo, usado a modo de muestreo la documentación inventariada en la serie Procesos Criminales II Parte del ARV, que contiene 893 procesos entre 1509 y 1701, se conservan 487 procesos del reinado de Felipe II, 332 de las décadas de 1560 y 1570, un 15\% de la documentación conservada en esta serie. Otras series del ARV que contienen procesos son: Procesos Criminales, Procesos de Madrid y Procesos Parte III Apéndice hasta el número antes mencionado de aproximadamente 6.000 procesos inventariados.

13 Furs, Capitols, Provisions, e Actes de Cort, fets y atorgats per la S.C.R.M. del Rey don Phelip nostre senyor ara gloriosament regnant en les Corts generals per aquell celebrades als regnicols de la ciutat y regne de Valencia, en la vila de Monco, en lo any MDLXXXV, València, MDLXXXVIII (Cortes de 1585) Fur, Cap., XII, f. IIII v. Edición facsímil a cargo de Salvador (1974).

14 FRV libro III, rúbrica V, fur LXVII.

15 Nos remitimos al análisis de las limitaciones y del del resto de competencias jurisdiccionales de la Real Audiencia como Alto Tribunal, competencias en materia de recursos y otras materias reservadas, a los estudios de Canet (1986: 118-135) y Matheu (1704: 19-31).

SCRIPTA, Revista internacional de literatura i cultura medieval i moderna, núm. 13 / juny 2019 / pp. 113 - 138 ISSN: $2340-4841 \cdot$ doi:10.7203/SCRIPTA.13.15477 
María Dolores Hernández-Fernández. Procesos criminales a instancia de parte privada. Apuntes sobre su praxis en el Real Consell Criminal valenciano en época de Felipe II

si era avocada al Real Consell Criminal en primera instancia resultaba juzgada indefectiblemente por este tribunal (Canet 1986: 119).

Hay que hacer una observación sobre el término avocación, ya que tiene varias acepciones. El sentido general es el de reclamar por el órgano jurisdiccional superior la resolución de un asunto cuyo conocimiento ya se ha iniciado por un órgano inferior. En este sentido, es claro que, a suplicación de cualquiera de las partes, se podía pedir la avocación desde otros órganos jurisdiccionales inferiores a la Real Audiencia en caso que entendieran que el asunto era competencia de esta. Pero el valor especial de la fórmula de la avocación que queremos comentar tiene un significado más amplio del que generalmente es entendido, el sentido es el de decreto y fue explicado en estos términos por Matheu (1704: 22): ${ }^{16}$

\footnotetext{
...Evocatio apud nos in quacumque causa, sive apud inferiorem initiata, sive de novo Senatum adducta, fieri solet, ita ut Evocare, apud nos, significet decretum quoddam, quo Dominus Regens vel Senatus pronuntiat causam ad cognitionem ipsius spectare, unde in lato significato hoc nomen sumitur.

Quo posito, cum regula fit, quod jurisdictio Senatus generaliter omnes causas comprehendir, inde est, quod generalis regula constituenda fit, ut omnes causae evocabiles dicantur.
}

Se puede hacer la lectura de que la avocación, entendida como decreto por el que la Real Audiencia se abroga el conocimiento de un asunto concreto, fue la solución de técnica jurídica adoptada por el alto tribunal con objeto de incardinar su actuación jurisdiccional criminal, en primera instancia, entre las instituciones regnícolas forales preexistentes con esta competencia, ya que había que articular jurídicamente lo previsto en la Pragmática de creación de la Real Audiencia de 30 de agosto de 1506, y la solución fue mediante un decreto del regente de la Cancillería. Este planteamiento en sentido positivo es confirmado por los mismos furs, por ejemplo, en las Cortes de 1564, y las pragmáticas, ordinacions y provisiones reales antes mencionados, que entre otras materias ordenan la actuación procesal criminal de este tribunal en primera instancia, ya que mencionan pacíficamente la avocación ante el Real Consell Criminal con este sentido de decreto. ${ }^{17}$ Tomando como premisa que esto fuese así cabe entonces preguntarse por el efectivo uso de esta avocación en los procedimientos criminales sustanciados ante la Real Audiencia, por quién se solicitaba y cómo y cuándo se materializaba.

La documentación analizada del Real Consell Criminal del ARV ${ }^{18}$ permite constatar que (en aquellas unidades documentales que son procesos criminales en primera instancia, siempre que lo permita su estado de conservación y se haya llegado a formular denunciació, clam e criminal acusació) contienen en dicho escrito la suplicación de la avocación por la parte actora y, al pie del mismo documento, el

16 Matheu publica su Tractatus de regimine Regni Valentiae entre 1654-1656, usamos para nuestro trabajo la edición en un solo volumen de Lyon de 1704.

17 ARV, RC, 601, Orde del Duch de Sogorb de 3 de Nohembre 1559, Cap. 30

18 De las décadas de 1560 y 1570

SCRIPTA, Revista internacional de literatura i cultura medieval i moderna, núm. 13 / juny 2019 / pp. 113 - 138 ISSN: 2340-4841 · doi:10.7203/SCRIPTA.13.15477 
María Dolores Hernández-Fernández. Procesos criminales a instancia de parte privada. Apuntes sobre su praxis en el Real Consell Criminal valenciano en época de Felipe II

decreto emitido por el regente sobre la admisión del conocimiento de la causa por la Real Audiencia, siempre que la denunciació, clam e criminal acusació reúna las condiciones de carácter procesal y material establecidas por furs para que se acepte.

En cuanto al momento procesal, la praxis observada en los procesos conservados nos lleva a distinguir varias situaciones. En primer lugar, encontramos procesos promovidos por particulares, iniciados por escrito de denunciació, clam e criminal acusació presentada ante el Real Consell Criminal en primera instancia. En los que los demandantes son los perjudicados por el delito o sus familiares, con la particularidad de ser mayoritariamente personas honestas, habitadors, incluidos menestrales de todos los oficios, de la ciudad de Valencia o su particular contribución, aunque también hay algunas causas interpuestas por nobles y caballeros. Los crims e injuries objeto de estos procesos puede ser cualquiera de los regulados por los furs siempre que sean de los castigados con gran pena corporal y/o son causas con presos, por tanto, no solo delitos privados.

En segundo lugar, observamos que el momento procesal es diferente en aquellos procesos en los que intervienen los procuradores fiscales, ya que el escrito de denunciació, clam e criminal acusació, es presentado al Real Consell criminal por el abogado fiscal, través de los procuradores fiscales después de haberse practicado necesariamente informació ex officio o inquisició por parte del Real Consell Criminal. Dentro de este grupo distinguimos tres casos, del primero Matheu (1704:289) nos dice “...crimina omnia, an possint persequi per inquisitionem in crimine privata, si corporalis pena debeatur per fiscum prosequis potest...". No hay denuncia formalizada solemnemente por el perjudicado, aunque sí encontramos procesos iniciados por clams verbals y procesos a instancia de part per inquisició. A estos últimos se les ofrece que formulen acusación formal y sí declinan o renuncian queda entonces su intervención como mero testigo de la notitia criminis y se plantea luego, en su caso, la denunciació, clam e criminal acusació por el abogado fiscal, pero se hace a través de los procuradores fiscales y tras la preceptiva informació ex officio o inquisició. Aunque mayoritariamente hemos observado que solo se prosigue el proceso si se trata de alguno de los casos fiscales. Un segundo grupo son los crímenes llamados casos fiscals, recogidos taxativamente en varios furs desde época de Jaime I. Según lo establecido en estos, y solo en estos casos tasados, la Cort, en este caso por tanto incluido el Real Consell Criminal, puede y debe, ex officio, averiguar y castigar. Pero también corresponde al abogado fiscal, a través de los procuradores fiscales, formular el escrito de denunciació, clam e criminal acusació, siempre tras haber realizado el Real Consell Criminal la preceptiva informació ex oficio, inquisició o emprisia sobre el crimen. ${ }^{19}$ Podemos decir, por tanto, a la luz de los furs que esté sería el ámbito competencial propio, por razón de la materia, del Real Consell Criminal. En estos casos el crimen puede haber sido cometido o los denunciados pueden ser, sorprendentemente, de cualquier lugar del Reino, incluidas gobernaciones, villas reales o lugares de señorío como, por ejemplo: Benirredrà, Xàtiva, Castelló, Alcira, Manuel, Soneja, Alcacer, Benavites, Albaida o Betxí. ${ }^{20}$

19 FRV, libro IX, rúbrica, fur XI-XIII.

20 Ver sobre el tema de la jurisdicción señorial las matizaciones que hace Febrer (1996: 438).

SCRIPTA, Revista internacional de literatura i cultura medieval i moderna, núm. 13 / juny 2019 / pp. 113 - 138 ISSN: 2340-4841 · doi:10.7203/SCRIPTA.13.15477 
María Dolores Hernández-Fernández. Procesos criminales a instancia de parte privada. Apuntes sobre su praxis en el Real Consell Criminal valenciano en época de Felipe II

Unos breves apuntes sobre estos crímenes cualificados. El grueso de casos fiscals viene establecido desde época de Jaime I:

\begin{abstract}
La Cort pot fer inquisició contra aquells qui son públicament infamats de homicidi, e de vici sodomítich, e de ladrocini, e desuahiment de cases, e de furt, e de rapina, e de trencament de camins, e de tala de camps, e de vinyes, e d'orts, e de foch a metre, e de crim de lesa magestat, e de falsadors de moneda, si a ell denunciació serà feyta, e no en altres coses. E feta la inquisició, e els dits testimonis reebuts e publicats, sia feta còpia de aquells e donat trellat a aquells contra los quals aquells testimonis seran donats, e dada còpia, o el translat, si poran dir contra los dits testimonis que sien hoïts. E si no, sia terminat lo pleyt. ${ }^{21}$
\end{abstract}

La nómina de casos fiscals fue ampliándose mediante sucesivos furs estableciendo supuestos específicos de competencia de órganos judiciales concretos. ${ }^{22}$ Su ámbito es amplísimo, por lo tanto, es difícil pensar en supuestos criminales que no se puedan reconducir a alguno de sus casos, quizás, a modo de ejemplo, las agresiones y nafres, las injurias de obra o palabra y los delitos que se podrían calificar ahora contra la libertad sexual: incumplimiento de promesa matrimonial, violación y estupro. Entre los casos fiscals destacan entre los procesos conservados los homicidios, casi la mitad, encontrándose ejemplos de todos casos fiscals en inferior proporción.

Queda un último grupo, que constituyen un tercio del total del material procesal conservado y cuya existencia plantea mayores problemas según los furs. Son iniciados mediante informacions ex officio o inquisició por el Real Consell Criminal sobre ilícitos que no son ni crímenes, ni injurias privadas, ni casos fiscals de los regulados en furs, pero que son sustanciados procesalmente del mismo modo que los casos fiscals, in similibus. ${ }^{23}$ Esto es mediante demanda formulada por el abogado fiscal, a través de los procuradores fiscales que formulan escrito de denunciació, clam e criminal acusació tras informació ex officio o inquisició practicada por parte del Real Consell Criminal. Estos ilícitos los podemos categorizar como delitos públicos, en estos procesos se ve claramente el carácter inquisitivo y los ilícitos, están definidos mediante diversas pragmáticas emitidas desde mediados del XVI y durante toda la época foral por diversos virreyes en el uso del ius puniendi. En general se trata de crímenes dirigidos al control y represión del problema morisco, la piratería y el bandolerismo. ${ }^{24}$ Prueba de que esto sucedía, son, además de los miles de documentos procesales conservados, los reiterados contrafurs planteados por los estaments, por ejemplo, durante reinado de Felipe II, donde los brasgos denuncian que los procuradors fiscals estén actuando por orden del virrey ex officio en crímenes que no son casos fiscals y se pide al rey que acabe con estos abusos. Pese a lo suscrito por vía de fur por Felipe II en

21 FRV, libro I, rúbrica III, fur XCIX

22 FRV, libro I, rúbrica III, furs C-CVIII.

23 Término usado por Matheu (1707: 289 y ss.) cuando habla de este supuesto.

24 Este problema amplísimo de la jurisdicción es uno de los temas que abordamos de la tesis doctoral que estamos elaborando sobre el proceso criminal ante la Real Audiencia valenciana.

SCRIPTA, Revista internacional de literatura i cultura medieval i moderna, núm. 13 / juny 2019 / pp. 113 - 138 
María Dolores Hernández-Fernández. Procesos criminales a instancia de parte privada. Apuntes sobre su praxis en el Real Consell Criminal valenciano en época de Felipe II

$1564^{25}$ tenemos constancia de que este tipo de procesos se siguen sustanciando hasta las siguientes Cortes de 1585.

En todos estos supuestos que hemos diferenciado, incluyendo todos los que tienen como parte actora a los procuradores fiscales y no están recogidos por fur, se atestigua el uso de la suplicación de avocación de la causa a la Real Audiencia en el escrito de denunciació, clam e criminal acusació junto con la de que sea encomendada a uno de los jueces de corte iuxta fori forma. El momento procesal oportuno es diferente en los distintos casos y depende del momento en que se puede plantear la demanda, con o sin informació ex oficio, pero manifestado del mismo modo y con la misma fórmula en el escrito de denunciació, clam e criminal acusació, tanto si el proceso es planteado por los particulares o por los procuradores fiscales, lo cual denota que la avocación estaba incorporada en la práctica al ritu en los procesos criminales sustanciados ante el Real Consell Criminal en las décadas de 1560 y 1570 en las que hemos centrado el estudio de los procesos conservados.

\section{Procesos criminales iniciados a instancia de parte privada en el Real Consell Criminal valenciano}

Analizaremos el proceso criminal de presencia a instancia de parte privada sustanciado ante el Real Consell Criminal, el primer grupo que hemos mencionado cuando hablábamos de la avocación. Interesa poder establecer el orde judiciari de estos procesos ordinarios, los menos complejos de los que se sustancian en el Real Consell Criminal e interesantes por cuanto perviven como una de las formas tradicionales de solución de conflictos, en el caso de que se trate de procesos por delitos privados perseguibles solo a instancia de la parte agraviada mediante la acusación (por ejemplo en el caso de injurias de hecho o de palabra, adulterio, violación, estupro o incumplimiento de promesa matrimonial), aunque también hay crímenes como las agresiones o nafres y casos fiscals como el homicidio, y cuya sustanciación está regulada por furs. Creemos que con ello se podrá estar en mejor disposición para comprender el resto de procesos en los que no se dan estas circunstancias y para dilucidar una posible especificidad procesal criminal de lo actuado ante la Real Audiencia valenciana en el contexto jurisdiccional regnícola ${ }^{26}$. Hemos usado para ello una selección de procesos criminales de la serie Procesos Criminales, I Parte y Procesos Criminales, II Parte del ARV de las décadas de 1560 y 1570, confrontándolos con lo regulado por furs, pragmáticas y ordinacions que regulan aspectos procesales y comentarios sobre algunas cuestiones procedimentales de Matheu (1704: 289-372). De entre los procesos conservados, los más completos, contienen la sustanciación hasta que el proces resta en punt de acort, encontrándose muy pocas ejecuciones.

25 (Cortes 1564) fur, Cap. LXXIII (Salvador 1974: 27).

26 El ordre judiciari del resto de procesos sustanciados en la Real Audiencia en los que observamos, en mayor o menor medida, intervención de los procuradores fiscales: a instancia de part per inquisició, por clam verbal o por casos fiscals e in similibus en los que se puede proceder ex mero oficio y que serán objeto de la tesis doctoral que estamos elaborando.

SCRIPTA, Revista internacional de literatura i cultura medieval i moderna, núm. 13 / juny 2019 / pp. 113 - 138 ISSN: 2340-4841 · doi:10.7203/SCRIPTA.13.15477 
María Dolores Hernández-Fernández. Procesos criminales a instancia de parte privada. Apuntes sobre su praxis en el Real Consell Criminal valenciano en época de Felipe II

Establecen los fur para todos los procesos que se sustancien en las “...corts dels ordinaris, o dels delegats del regne de València, sia enantat sens tota figura de juhí, attesa solament la veritat del feyt..." no pudiéndose pedir la nulidad incluso en el caso de carecer de alguna parte esencial: “... oblació de libell, contestació solemne de pleyts e prestació de sagraments de calúmnia...". ${ }^{27}$ Sin embargo, en el procesamiento de ciertos crims (crímenes públicos) e injuries (crímenes privados) castigados con penas corporales y/o por los que se puede pedir y solicitar por el denunciante el apresamiento del inculpado para practicar la prueba de confesión, sí se establecen una serie de requisitos de procedimiento que se han de cumplir taxativamente bajo pena de nulidad de lo actuado. Éste es el tipo de crímenes del que conoce la Real Audiencia, en la época que estamos analizando, ya que como vimos, solo se podían avocar aquellos que estuviesen castigados con pena corporal grave.

Por lo tanto, en principio debe cumplirse, también por el Real Consell Criminal, lo establecido en furs sobre la sustanciación de los procesos castigados con las más graves penas corporales y por los que se puede pedir y solicitar por el denunciante el apresamiento del delat. Se trata del caso de “...si algú serà accusat d’omicidi, o de qualque altre crim o malefici, del qual, si serà provat que fos ver, aquel qui serà accusat deja morir..." estableciendo que no debe permanecer en prisión sin “...apparexent presumpció o manifesta suspició...” por lo que la cort debe “...ell destrenyer que li do fermances ..." de cierta cantidad. ${ }^{28}$ Pero en el Fur de Jaime I no se establecía ningún procedimiento, este se introdujo por Fernando II. En las Cortes de 1564 en la parte expositiva del fur LXIIII, ${ }^{29}$ a petición de los tres brazos, se aborda el tema de cuando "....algú serà pres per crim per ell comés...” en proceso criminal de presencia ampliándose los supuestos a todos los procesos en los que el demandado sea susceptible de estar preso:

\footnotetext{
Item, Senyor, com la expedició dels processos y causes criminals que s tracten en dita ciutat y regne sia molt necessària, perquè altrament los súbdits y vassalls de vostra magestad serien indebitament vexats y molestats, per la qual rahó lo sereníssim e cathölich rey don Ferrando, de alta recordació, com a zelós del que convenia y convé a la bona administració de la justícia, ab un fur per aquell fet en les corts celebrades en la ciutat de Oriola, que comença, Declarant, e millorant, dona cert orde... en la prosecució, decisió e determinació de dits processos y causes criminals...
}

El fur citado de Fernando II de las Cortes de Orihuela de 1488 establece un procedimiento de plazos para todos los casos en que alguien esté preso por delito cometido por el mismo distinguiendo varios supuestos: $:^{30}$

27 FRV, libro I, rúbrica III, furs VII-XI y rúbrica VI, fur V.

28 FRV, libro IX, rúbrica VII, fur XVIII.

29 Cortes de 1564, Fur, Cap. LXIII, f. VIII v. y IX r.

30 FRV, libro IX, rúbrica VII, fur XIX.

SCRIPTA, Revista internacional de literatura i cultura medieval i moderna, núm. 13 / juny 2019 / pp. 113 - 138 
María Dolores Hernández-Fernández. Procesos criminales a instancia de parte privada. Apuntes sobre su praxis en el Real Consell Criminal valenciano en época de Felipe II

\begin{abstract}
Declarant e millorant e enadint als furs fets en lo present Regne en rübriques de crims, volents donar deguda forma al procehiment que s deu fer en aquells per tolre vexacions als nostres súbdits e vassalls, provehim e ordenam que si algú serà pres per crim per ell comés, del qual no sia deguda pena corporal, dins deu jorns contínuament comptadors après que serà denunciat o lo clam serà posat, li sia fet e clos lo procés, sens dilació alguna. E li sia donada la pena pecuniària que merexerà, ab sentència. E si lo jutge o lo oficial davant qui seraà lo procés, no donarà sentència dins lo dit temps, sia encontinent delliurat e absolt lo pres del dit crim e pena; e lo tal official o jutge pague lo interès al dampnificat...
\end{abstract}

En esta primera parte se establece un procedimiento para los delitos que no conllevan pena corporal sino tan solo pena pecuniaria, por el cual se puede estar preso para asegurar su comparecencia en el proceso, con lo que se amplía a prácticamente a casi todos los procesos incluso los procesos civiles por deudas. Es un procedimiento de 10 días a continuación de que sea denunciado o puesto el clam.

En una segunda parte, se regula el procedimiento para los delitos que merezcan pena corporal:

\begin{abstract}
...E si lo crim o delicte ser $\grave{a}$ tal que mereixca pena corporal principalment o en subsidi, en tal cars tot lo procés haja esser fet dins terme de quaranta dies contínuament comptadors. En axí, emperò, que si dins los cinch dies primers no serà mostrat per lo accusador alguna cosa per la qual se mostren vehements o aparexents presumpcions contra lo delat, encontinent done a sufficient fermança lo delat e tragua aquell de la presó. Los dits cinch dies volem que correguen del dia en avant que serà confessat lo delat, e correguen ipso facto fetes les confesions, sens fer-hi provisió...
\end{abstract}

Se establece, por tanto, en el caso de que “....algú serà pres per crim per ell comés... per crim o delicte... que mereixca pena corporal..." que los plazos sean de 40 días, pero estableciéndose que en los primeros 5 días el acusador debe haber mostrado de algún modo que, al menos, hay alguna presunción en contra el acusado. Este plazo de 5 días debe empezar a correr desde la confesión del delat y de modo ipso facto.

...En axí que, passats los dits cinch dies après que lo delat serà confessat, sia lo jutge solícit en fer-se venir lo scrivà, per veure que és provat contra lo dit delat. E, segons lo que trobarà, retinga o delliure aquell dit delat, segons dessús és dit, no obstant res en contrari al leguat. E si deurà esser detengut pres fins a sentència, aquella dita sentència sia donada dins lo dit terme de XL dies...

A continuación, según lo actuado en esos cinco días el juez debe determinar la libertad o no del encausado, siempre con las suficientes garantías, si así lo estima el juez a su arbitrio “...E lo pres sia delliurat e donat a bones e sufficients fermances de presentar aquell, tota hora que sia demanat..." o continuar preso hasta la sentencia. Remarca el fur que el plazo de 40 días para dictar sentencia rige en caso que se estime que el inculpado deba continuar en prisión: 
María Dolores Hernández-Fernández. Procesos criminales a instancia de parte privada. Apuntes sobre su praxis en el Real Consell Criminal valenciano en época de Felipe II

\begin{abstract}
...E volem encara que les dilacions a posar e provar e publicar sentència dessús dites, no puixen ésser més de XL dies, y aquells correguen ipso facto, del dia en avant que lo delat serà stat confessat; e lo dit terme puja ésser abreujat, segons la qualitat del crim e no perlongar...
\end{abstract}

Por tanto, en caso de prisión la sentencia debe de ser dictada inexcusablemente dentro del plazo de 40 días, incluyendo en este término, todas las pruebas o dilacions que restaran por realizar que antes se había mencionado. Prohibiendo que en todo caso se alarguen los plazos en las dilacions, aunque sí se pueden acortar. En la última parte del fur se señala que, en todo caso, necesariamente la denuncia y la confesión del delatado debían ser dentro de los 2 días siguientes a que entrase en prisión, se entiende para los casos en que no estuviese preso desde el principio "...Açò emperò declarat, que dins dos dies après que serà algú pres sia denunciat, e confessat, e sia lexada la denunciació en poder del scrivà...". Esta farragosa redacción, cuando menos, hubo de causar problemas de interpretación. Por ello no es de extrañar que resultaran necesarias aclaraciones en Cortes posteriores, como se recuerda en la súplica del fur LXIIII las Cortes de 1564 que estamos transcribiendo:

...Per ço los dits braços supliquen a vostra magestat, sia servit provehir y manar que axi lo dit fur del dit sereníssim rey cathölich com dos actes de cort en aprés fets en les corts celebrades en lo any M.D. XXVIII, lo hu dels quals comença, Primo, per rellevar, e lo altre, Item señor, ab lo mateix fur \&...

Estos dos actes de cort de las Cortes de 1528 que se mencionan aclaran a sensu contrario los problemas de interpretación que generó el farragoso fur del Católico, en cuanto al término de dos días para presentar acusación y tomar confesión al acusado. Ambos recogidos en los Fori Regni Valentiae. ${ }^{31}$ Así, en la parte expositiva del primero de ellos se dice:

Primo, per rellevar los súbdits e vassalls de danys e despeses e tolre vexacions, per lo alt e cathölich rey don Ferrando, en les corts celebrades, en lo fur primer, situat en rubrica de crims, és provehit e ordenat que lo qui serà pres dins dos dies après que serà pres, sia denunciat e confessat e la denunciació dexada en poder de l'escrivà. Lo qual fur no serven los officials de sa magestat perquè per clara e notòria speriència se és vist que molts són presos a instància de part privada o del fisch, e ls tenen presos hun mes e dos mesos y molts mesos, sens posar contra aquells acusació ninguna, lo que es grandíssima vexació per als súbdits e vassalls de sa magestat e causar les grandíssimes despeses e dans intol lerables...

Y es que, si se atendía solo a las primeras líneas del fur de las Cortes de Orihuela de 1488, haciendo una interpretación torticera prima facie, parecía quedar al arbitrio del acusador el momento de hacer la acusación y en ese caso el preso podía permanecer en la prisión sine die sin hacerse ninguna actuación. Por otra parte, en este acte de cort se propone como solución que el incumplimiento de los plazos signifique imposición de sanciones para el demandante, que el rey no acepta. Tampoco se aceptará en el acte de cort XXVIII ${ }^{32}$ de las Cortes de 1528 por lo que sigue vigente en su totalidad el fur del Fernando II

31 FRV, libro IX, rúbrica VII, furs XXVII y XXVIII.

32 FRV, libro IX, rúbrica VII, fur XXVIII.

SCRIPTA, Revista internacional de literatura i cultura medieval i moderna, núm. 13 / juny 2019 / pp. 113 - 138 
María Dolores Hernández-Fernández. Procesos criminales a instancia de parte privada. Apuntes sobre su praxis en el Real Consell Criminal valenciano en época de Felipe II

\begin{abstract}
...provehir e ordenar que la dilació de quaranta dies sia pera instruhir lo procés, passats los quals ipso facto reste en punt de acort e que dins vint dies après sia donada sentència, restant totes les altres coses en lo dit fur ordenades en sa força e valor en lo que no deviaran ne seran contràries al que en la present cort serà provehit e ordenat...
\end{abstract}

Destacamos que señalan los brazos de modo llano que el fur del Fernado II también es de obligado cumplimiento por la Real Audiencia, ya que no se dice que "se deba aplicar" sino que está siendo mal aplicado y se pide que:

\begin{abstract}
... sien ad unglem observats y guardats juxta lur continència sèrie, e tenor, e que qualsevol jutges y officials, per grans e preheminents que sien, de dita ciutat y regne (...). Lo qual fur [el de Fernando el Católico] per los officials de vostra magestat és estat mal observat e guardat, perquè de molts anys ençà, los dits jutges y officials han contravengut al dit fur, axí en lo temps de la prossecució com de la decisió de dites causes. Per hon vostra magestat tenint, com té, lo mateix zel que lo sereníssim y cathölich rey don Ferrando, vist que lo dit fur de cascun dia se abusava, ab sa real y patent letra manà als doctors de la Real Audiència, que observasen y guardasen dit fur a la letra, lo que tampoch no és estat inseguit...
\end{abstract}

Cuando se establece este fur de 1488 recae, en principio, sobre los justicias, como juez ordinario, la mayor parte de los procesos criminales. En la parte final del mismo Fernando II adopta una serie de resoluciones para solventar la cuestión práctica de cómo y cuándo habían de dar sentencia los justicias de las ciudades y villas reales. Se recuerda que no podían dar sentencia como establecían los furs “...sens lo Consell general, e differint-se lo consell se differeix la justícia..." y por tanto no se podía “...fer lo que dessús és dit e ordenat dins lo dit temps...”, por tanto se establece y ordena “... que almenys cascun divendres de cascuna semana sia tengut Consell General per les coses criminals, en los quals dies se determenen les dites causes". El problema en 1488 era que no se reunía el Consell General con el justicia criminal el suficiente número de días para la rápida expedición en plazo de los procesos, y lo que sucedía por este motivo (aparte de las molestias causadas a aquellos que permanecían presos en espera de sentencia) podía ser que los jurados fueran compelidos a reunirse “...per lo portantveus de governador e cort sua, axí deçà com dellà Sexona, o lochtinents generals e particulars de aquells, ab manaments penals e execució de pena...". Para evitar estos conflictos Fernando II señala un día concreto para la celebración de estos actos. Estableciendo una excepción para la ciudad de Valencia, de modo que para aquellos delitos que no estuviesen castigados con "... pena corporal de mort, mutilació de membre..." pudiera dictarse sentencia con el consejo "...de son ordinari assessor tant solament sens convocar Consell general...”.

Las Cortes de 1564, en el cap. XXX, ${ }^{33}$ en el mismo sentido también pretende asegurar lo relativo al tiempo y lugar en el que ha de reunirse la sala criminal para la correcta expedición de las causas; por lo tanto, se da el mismo tipo de solución que Fernando II adoptó, ${ }^{34}$ pero en este caso para las

33 Cortes de 1564, fur, Cap. XXX, (Salvador 1974: 17)

34 Solución que también había adoptado Carlos I tras las Germanías, aunque no de modo completo en la Pragmática super ordinationes Rotae de 9 de octubre de 1527, ARV RC, Reg. 1315, transcrito por Canet (1986: 197-201).

SCRIPTA, Revista internacional de literatura i cultura medieval i moderna, núm. 13 / juny 2019 / pp. 113 - 138 
María Dolores Hernández-Fernández. Procesos criminales a instancia de parte privada. Apuntes sobre su praxis en el Real Consell Criminal valenciano en época de Felipe II

causas a sustanciar en la Real Audiencia:

\begin{abstract}
...que per a la decisió y determinació de les causes criminals los dits regent, jutges de cort y advocat fiscal se hajen de ajustar tres dies en la semana, los après dinars tant solament, en casa del dit regent o del lochtinent y capità general, o regent la lochtinència general en la dita ciudat y regne, y que en lo dit loch y temps se voten y determinen dites causes, hi 's facen les visites dels presos per los dits jutges de cort o per altre de aquells.
\end{abstract}

En este caso el fur sí es aceptado por el rey con la fórmula "Plau a sa magestat", aunque con salvedades, ya que se establece “...si ja al virrey no li parexera que ss tinga criminal en los altres días...", por lo que pueden ser ampliados. También se contempla un sistema de sustituciones ya que al monarca le interesa para la expedición de los procesos prever los casos de ausencias, se dice que "...lo més antich presida, quant lo regent no asistirà, axí en lo civil com en lo criminal..." salvando, por último, la autoridad del virrey sobre la Audiencia cuando se añade “... y que lo dit regent puga presidir en qualsevulla de les sales segons li parexerà y ordenarà lo virrey."”

De todo lo dicho se puede deducir que los puntos claves en el proceso criminal, cuando se trata de delitos castigados con las más graves penas corporales y/o con preso, regulado por furs son: la denuncia formal del demandante por medio de denunciació, clam e criminal acusació o libello, la prestació de sagraments de calúmnia, la contestació solemne de pleyts. ${ }^{35}$ En este caso añadiendo además un sistema de plazos para realizar la confesión, establecidos para evitar los abusos y vejaciones que se estaban cometiendo a su calor con ánimo de calumniar y vejar, pero también trámite necesario para poder llegar a establecer las posiciones de las partes en relación con lo que se denuncia, a modo de litis contestatio como nos dice Matheu (1704: 306).

Analizaremos cada uno de estos cabos que constituyen el proceso criminal de delitos castigados con pena corporal grave y/o con presos. La Cort, (y por tanto el Real Consell Criminal), según furs, admite los escritos de acusació, clam y criminal denunciació presentados por particulares, siempre que fuese persona honesta y el acusado de humilde condición, fuese sospechoso y se diesen sagraments iuxta fori forman por el demandante. La sentencia será nula en caso de que no se proceda así. ${ }^{36} \mathrm{De}$ modo que, dependiendo de la condición del acusador, bastan según furs con estas cauciones para interponer acusació, clam y criminal denunciació incluso en el caso de que se trate de casos fiscals, cosa que lamenta Matheu (1704: 298) ya que para interponer acusació, clam y criminal denunciació por el abogado fiscal, a través de los procuradores fiscales es necesario en todo caso realizar previamente la preceptiva informació ex officio o inquisició por la Cort y aunque se trate del Real Consell criminal no queda eximido aún en el caso de in fraganti.

Veamos primero la demanda. Por acusació, clam y criminal denunciació se entiende informar de modo debido la comisión de un crimen y del inculpado del mismo. En los escritos de acusación, según vemos en la praxis, siempre se incluyen todos los términos. Se presenta por escrito, sin datación,

35 FRV, libro I, rúbrica III, furs VII-XI y rúbrica VI, fur V.

36 FRV, libro IX, rúbrica I, furs I-VIII.

SCRIPTA, Revista internacional de literatura i cultura medieval i moderna, núm. 13 / juny 2019 / pp. 113 - 138

ISSN: 2340-4841 · doi:10.7203/SCRIPTA.13.15477 
María Dolores Hernández-Fernández. Procesos criminales a instancia de parte privada. Apuntes sobre su praxis en el Real Consell Criminal valenciano en época de Felipe II

firmada por abogado ante el Real Consell Criminal, en forma de supplicació de denunciació, siempre encabezada con la expresión accusats públicament infamats requisito desde antiguo establecido para poder procesar en Valencia (que encontramos en todas las demandas, incluidas las de los procuradores fiscales y para todo tipo de crímenes). La denunciació, clam e criminal acusació o libello, debe contener el nombre del demandante su domicilio su condición de persona honesta y/o profesión, y en caso de ser mujer se indica de qué hombre es esposa, madre, o hija y la profesión de éste. ${ }^{37}$ En cuanto a la persona del demandante se ha de solicitar licencia a la Cort en caso que se quiera pleitear por parte de un hijo o de un siervo contra su señor, y no pueden "....metre en plet a son pare per cosa famosa o criminal..." mientras estén sometidos los hijos a patria potestad y los cautivos, aunque hayan sido liberados y se hayan convertido. Fernando II en las Cortes de 1510 y Carlos I en las de $1542^{39}$ establecen más limitaciones, ya que no se ha de permitir que pleiteen entre “... pares, mares, fills e filles, germans e jermanes, e marits e mullers...” y deben quedar sujetos a “... fermar compromés dels pleyts e causes..." que entre ellos se traten para evitar los grandes gastos que ocasionan y las grandes "...inimícicies e males voluntats...".

En la demanda se ha de acusar directamente a personas concretas con la expresión “...yo, aytal, accús aytal... de tal crim, que si provat era, degués prendre pena corporal...". ${ }^{40}$ Los delitos de que se acusa (por los que puede estar preso antes de presentarse la demanda o por los que se puede solicitar un futuro apresamiento con el objeto de que comparezca en el acto de la confesión judicial) se exponen a modo de relación de los hechos que se quieren probar, organizados por capítulos, y que deben incluir todas las cualidades del delito que se quiere denunciar. Pero también las del sujeto demandado, se suele incluir circunstancias que hablan de su vil condición o su mala vida. Entre los procesos estudiados hay casos de nafres ${ }^{41}$ incumplimiento de promesa matrimonial y estupro (de un aprendiz respecto de la hija de su maestro) ${ }^{42}$ rapto y violación (de un escuder sobre la esclava de su amo) ${ }^{43}$ y furt con rapina (entre dos llauradors) los dos últimos crímenes casos fiscals. ${ }^{44}$ Debe ser cierta, específica y clara, es decir, que se pueda probar. Presentar apparexent presumpció o manifesta

37 Dejamos para otro lugar el estudio de las especificidades del proceso cuando el demandante es viuda, huérfano o personas miserables. Un ejemplo de mujer demandante en ARV, Procesos Criminales II Parte, reg. 201 de 1565.

38 FRV, libro II, rúbrica II, furs I-II.

39 FRV, libro II, rúbrica II, furs III-IV.

40 FRV, libro IX, rúbrica I, fur II.

41 ARV, Procesos Criminales II Parte, reg. 207 de 1566 y 201 de 1565.

42 ARV, Procesos Criminales II Parte, reg. 232 de 1568

43 ARV, Procesos Criminales II Parte, reg. 206 de 1566.

44 ARV, Procesos Criminales II Parte, reg. 241 de 1569.

SCRIPTA, Revista internacional de literatura i cultura medieval i moderna, núm. 13 / juny 2019 / pp. 113 - 138

ISSN: 2340-4841 · doi:10.7203/SCRIPTA.13.15477 
María Dolores Hernández-Fernández. Procesos criminales a instancia de parte privada. Apuntes sobre su praxis en el Real Consell Criminal valenciano en época de Felipe II

suspicio $^{45}$ que pueda justificar la denunciació, clam e criminal acusació presentada por el demandante. La división en capítulos es necesaria para facilitar que los acusados puedan efectuar su derecho de defensa, también las testificales se han de constreñir solamente a los capítulos y la sentencia debe ser conforme al libello efectuado por la parte, aclara Matheu (1704: 306).

Se incluyen en la demanda varias súplicas: la más importante es la de que se confiese al demandado. $\mathrm{Al}$ respecto se indica, en su caso, sí el delat está ya preso en las cárceles reales y en caso de que no estarlo, se suplica que se emita mandamiento de captura, para que una vez preso preste confesión judicial mediante comparecencia ante el juez relator de la causa sobre los capítulos incluidos en la denuncia. En caso de que no se pueda detener, se suplica que se prosiga la tramitación del proceso en ausencia iuxta fori forma. ${ }^{46}$ Otra de las suplicas es que si de las confesiones y resto de pruebas constara haber fes y comes, los dichos crímenes y delictes (casi siempre sin mencionar tipos determinados, aunque hay excepciones $)^{47}$ se pide que se condene al autor o los autores a las penas corporales, civiles y pecuniarias establecidas por furs, privilegios, pragmáticas, usos y buenas costumbres del present regne, condenando en la pena debida (no se piden penas concretas) y en las expensas de la causa, para lo que se pide que los bienes muebles del delat sien scrits y anotats. Y, por último, se suplica la avocación al Real Consell Criminal y que sea "...manada cometre a un dels magnífichs doctors de la Real Audiència ad colligendum et referendum super intermedis et aliis necessariis et de oportuna comissione debie providere...".

Siempre consta al pie de la acusació, clam y criminal denunciació el decreto por el que se acepta la avocación por el Regente, como ya habíamos apuntado. Cuando esta se admite se hace llanamente y siempre tiene la siguiente fórmula: "Evocata causa denunciationis magnifich... (nombre del juez relator asignado) ... audiat, colligat et referat et super intermedis et aliis necessariis debite provideat", aceptada por el regente de la Real Audiencia y firmada por el escribano del mandamiento de la causa como notario haciendo constar la fecha. Se dicta a continuación, de mano del propio relator, la provisión Registrata et dicto die fiant supplicata.

Veamos ahora los sagraments, otro de los elementos imprescindibles en las demandas presentadas por particulares, en la praxis procesal. ${ }^{48}$ Son varios y no se trata solo de la prestació de sagraments de calúmnia. Se realizan aparentemente en una única comparecencia, en un mismo día y aparecen en el proceso en forma de acta a continuación del escrito de acusació, clam y criminal denunciació. Una vez personado el demandante (también las mujeres demandantes) ante el relator (o ante un alguacil por comisión verbal del relator) es levantada un acta que incluye cada uno de los sagraments sobre los que el demandante es interrogado bajo juramento iuxta forma de fur, sosteniendo en la mano derecha y

45 FRV, libro IX, rúbrica VII, fur XVIII.

46 FRV, libro IX, rúbrica I, furs XI-XII.

47 ARV, Procesos Criminales II Parte, reg.241 de 1569 en el que se califica los hechos de furt y rapina, dos casos fiscals.

48 ARV, Procesos Criminales II Parte, reg. 201 de 1565; 206 y 207 de 1566; 232 de 1568; 241 de 1569.

SCRIPTA, Revista internacional de literatura i cultura medieval i moderna, núm. 13 / juny 2019 / pp. 113 - 138 ISSN: $2340-4841 \cdot$ doi:10.7203/SCRIPTA.13.15477 
María Dolores Hernández-Fernández. Procesos criminales a instancia de parte privada. Apuntes sobre su praxis en el Real Consell Criminal valenciano en época de Felipe II

besando los Sagrados Cuatro Evangelios y ante la presencia de dos testigos, cuyos nombres constan al pie del acta, normalmente particulares con diversos oficios, y podemos especular, conocidos de los denunciantes, aunque en algunos casos se reconocen nombres de personal de la Real Cancillería.

El orden puede variar, pero todos los procesos instados por parte privada contienen los distintos sagraments establecidos en furs: Se le pregunta sobre “...qui havia ordenada la dita denunciació..." ya que la denunciació, clam e criminal acusació se presenta con rúbrica de abogado, pero su nombramiento se hace en este acto, mediante juramento, (aunque también hay algunos poderes para pleitos unidos a los procesos), siempre doctor en cascun dret y residente de la ciudad de Valencia. El acta continua con la pregunta sobre si la denuncia “...és posada per odi, rancor e mala voluntat o per calumniar, vexar e molestar..." al que denuncia a lo que siempre se contesta que el clam se ha puesto por obtener justicia, según se establece por fur respecto a los clams que se presenten los vebins de Valencia. ${ }^{49}$ También se le hace jurar que “...durant la present causa de denunciació no eixirà de totes les terres de la sacra cathòlica real magestat del rey nostre señor, haver deçà la mar...". ${ }^{0}$ En relación con la avocación, y asegurando cualquier cuestión de jurisdicción, por lo menos por la parte actora, jura la renuncia al fuero propio o juez ordinario que tuviese, y da la llamada fermança de dret afianzando el cumplimiento de las obligaciones derivadas de la demanda. ${ }^{51} \mathrm{Y}$, por último, el denunciante se obliga a la poena talionis ${ }^{52}$ con el delat y denunciat de la que, según establecen los furs, se distingue el caso de que se demostrase mala fe en la demanda y fuese condenado, cuando se hubiese pedido pena corporal “...que aquel qui accusara soffirà aquella pena...”, del resto de acusaciones de las que se establece que “....sia tengut lo accusador de redre les despeses a l'accusat que haurà feytes per aquella rahó, pus lo accusador no li ho pusque probar..." incluidos en este último caso las renuncias de acciones, dando fermança suficiente a criterio de la Cort. ${ }^{53}$ Por tanto, se ha de dar caución suficiente de solvencia para cubrir las expensas del proceso y para el caso de que fuese condenado por calumnia, y por lo que se obligaba dando fermança $a^{54}$ ante el baile con todos sus bienes presentes y futuros se encontrasen donde se encontrasen, y en concreto en la mayoría de casos vistos se establece “... sot pena de mil florins de or...”. Se cita siempre en la praxis en este apartado de prestación de sagraments de calumnia la normativa que regula la pena de talión: la Pragmática de Alfonso V de 9 de enero de 1437 y el fur de Fernando II de $1488,{ }^{55}$ que establece esta obligación en todas las instancias incluyendo la renuncia a su fuero propio para esta cuestión. Por último,

49 FRV, libro I, rúbrica II, fur V.

50 FRV, libro IX, rúbrica I, fur XX.

51 FRV, libro I, rúbrica II, fur V.

52 FRV, libro IX, rúbrica I, furs I-VII.

53 FRV, libro I, rúbrica V, furs XIII.

54 FRV, libro IX, rúbrica I, fur VI.

55 FRV, libro IX, rúbrica I, furs III y IV.

SCRIPTA, Revista internacional de literatura i cultura medieval i moderna, núm. 13 / juny 2019 / pp. 113 - 138 ISSN: 2340-4841 · doi:10.7203/SCRIPTA.13.15477 
María Dolores Hernández-Fernández. Procesos criminales a instancia de parte privada. Apuntes sobre su praxis en el Real Consell Criminal valenciano en época de Felipe II

aparece el nombramiento de procurador, que se hace también mediante juramento en un acta a continuación de la anterior, ante dos testigos y siempre de forma separada para cada procurador que se nombre, en ocasiones en fecha posterior.

De la fecha de realización de los sagraments, incluida la suscripción de la pena de talión y de la fermança de cubrir los gastos del proceso se hace una nota al pie del escrito de acusació, clam y criminal denunciació, debajo del decreto de avocación del regente, además suscrita con su firma por el abogado fiscal que se ha dado "...fermança en poder del batle de pagar les messions del plet si no s provarà ço que haurà denunciat..." ${ }^{56} \mathrm{El}$ cumplimiento y fermança de todos los sagraments possa calendari al escrito de acusación y permite que se dé curso a la demanda.

El otro aspecto básico en el proceso criminal de delitos castigados con pena corporal grave y/o con presos es que se realice la contestació solemne de pleyts (en caso de procesos criminales, la confesión del demandado), elemento convertido en esencial por Fernando II en este tipo de causas en las que el apresamiento del inculpado será el modo de asegurarse la presencia del mismo para realizar la prueba de confesión y que empiecen a correr los plazos. Sobre los presos indicar que los furs permitían que un delat pudiera estar preso en caso de delito flagrante (Matheu 1704: 297), circunstancia por la que cualquier persona podía detenerle para llevarlo a la Cort $^{57}$ o como también podía hacerlo un alguazir ya que podían ejercer su oficio de "...presó e de anotació de bens..." donde fuese demandado su auxilio por “...requesta que li serà feta verbal...” a instancia de parte, en la ciudad de Valencia y su contribución, con la obligación de comunicarlo al vicecanciller al día siguiente. En la praxis del XVI ante uno de los jutges de cort. Por otra parte el Orde del Duch de Sogorb de 3 de Nohembre 1559, en el Cap. $30^{58}$ establece que no se admitirá ninguna denuncia criminal en primera instancia contra personas que son “...fora de la present ciutat y contribució d'ella, puix tenen sos jutges ordinaris...", pero sí por alguna justa causa se ha de admitir se obliga a que además de cumplir con las “...solemnitats per fur requerides... no sien presos, ni se’ls mane compareguen personalment los tals denunciats, sens que preceheixca informació sobre..." la causa y motivo por el que se avoca a la Real Audiencia, pues “....moltes voltes se fan les evocacions per vexar les tals persones." Es el caso que mencionamos anteriormente de procesos a instancia de part per inquisició en los que intervenía el procurador fiscal junto con la parte y que puede explicar la ausencia de procesos interpuestos por particulares de asuntos de fuera de la ciudad de Valencia o de su particular contribución.

De modo que una vez avocada la demanda y cumplido del trámite de los sagraments, nos encontramos ante dos supuestos. En el caso que el delat esté preso, se le lleva ante el relator para realizar la confesión llamada super denuntiatione, respondiendo sobre la verdad o no de cada uno de los capítulos

56 FRV, libro IX, rúbrica I, fur VI.

57 FRV, libro I, rúbrica VII, fur I-VI.

58 ARV, RC, 601, ff. 157.

SCRIPTA, Revista internacional de literatura i cultura medieval i moderna, núm. 13 / juny 2019 / pp. 113 - 138 ISSN: 2340-4841 · doi:10.7203/SCRIPTA.13.15477 
María Dolores Hernández-Fernández. Procesos criminales a instancia de parte privada. Apuntes sobre su praxis en el Real Consell Criminal valenciano en época de Felipe II

de la demanda exclusivamente. No hay repreguntas del relator. El fur de Fernando II $^{59}$ que regula las causas con presos establecía “...en axí que, passats los dits cinch dies après que lo delat serà confessat, sia lo jutge solícit en fer-lo venir lo scrivà per veure que és provat contra lo dit delat...”; en la práctica ante el Real Consell Criminal hemos visto que esto se traducía en que los procesos a instancia de particulares se iniciaban siempre con la acusació, clam y criminal denunciació, en la que por principio constaba apparexent presumpcio o manifesta suspicio y en cuyo tenor se hacía constar la circunstancia de que el delat ya estaba preso a efectos de ser confesado, aunque no se hacía constancia de la fecha; el preso normalmente era confesado dentro del plazo de cinco días desde que se formalizaban los sagraments en los casos que hemos visto. ${ }^{60} \mathrm{El}$ otro supuesto era cuando no estaba preso el delat, por lo que se ordena su apresamiento, aunque esta diligencia no consta en los procesos, a no ser que haya sido negativa, ya que este trámite es el que inicia el proceso en ausencia; pero por estos procesos (muchísimos, de hecho es difícil encontrar procesos instados por particulares que no se dé la circunstancia de que el demandado esté huido) sabemos que tales diligencias son efectuadas por los alguaciles reales, a suplicación del demandante pero ha de ser avalada por los procuradores fiscales y aprobada por el regente de la Real Audiencia. Una vez detenido, se procede a la confesión judicial, de la que consta la fecha, pero no sabemos la de la detención.

Una vez han sido hechas las confesiones judiciales, en el mismo día el relator de la causa las da por publicadas y provee que se inserten en el proceso y se dé traslado a la otra parte y se haga copia en el caso que lo pida. A continuación, en el mismo acto, se otorga a las partes un plazo común de diez días de dilación para pruebas en materia principal y cinco días en materia objetiva para que durante las dichas dilaciones se hagan las testificales y otras pruebas que soliciten. Estos plazos forman parte de la praxis, no se regularán por fur hasta las Cortes de 1604, por lo que se mencionan expresamente en todos los procesos estudiados.

En el mismo día de la confesión y una vez abierto el periodo de dilaciones, el delat y denunciat nombra abogado y procurador mediante juramento, de la misma forma que los demandantes, mediante un acta formalizada ante dos testigos que firman al pie. A continuación, y a suplicación del procurador del demandando, se pide que el procesado salga de prisión, o se solicita, en caso de haberse presentado voluntariamente, ${ }^{61}$ quedar bajo arresto en una casa de la ciudad de Valencia, a disposición del tribunal, bajo pena pecuniaria variable a criterio del jutge de cort. Normalmente se establecía una cantidad que oscila entre las veinticinco y las cien libras valencianas. Y también bajo caplleuta de dos hombres honestos, que asisten al acto, y que responden económicamente por el delat bajo juramento, comprometiéndose en asegurar que el procesado no abandonará dicha casa y se

59 FRV, libro IX, rúbrica VII, fur XIX.

60 ARV, Procesos Criminales II Parte, regs.206 y 207 de 1566; 232 de 1568 en el mismo día en que se prestan los sagraments por la parte demandante.

61 ARV, Procesos Criminales II Parte, reg. 241 de 1568.

SCRIPTA, Revista internacional de literatura i cultura medieval i moderna, núm. 13 / juny 2019 / pp. 113 - 138 ISSN: $2340-4841 \cdot$ doi:10.7203/SCRIPTA.13.15477 
María Dolores Hernández-Fernández. Procesos criminales a instancia de parte privada. Apuntes sobre su praxis en el Real Consell Criminal valenciano en época de Felipe II

presentará ante la Cort cuando sea necesario. Así mismo, el procesado y los capllevadors renunciaban a su propio fuero sobre todas las cuestiones judiciales derivadas y se sometían a la Real Audiencia mediante fermança de dret. De este modo el procesado también se somete a sagrament y homenaje, como el demandante, ya que bajo juramento ante el alguacil designado por el relator prometía “... eixir de la present sala daurada..." la de la Casa del Consell de la ciudad de Valencia, donde en la mayoría de ocasiones consta que se realizaban actos del Real Consell Criminal (también puede ser en casa del relator) para dirigirse al lugar del arresto domiciliario, cuya situación en la ciudad de Valencia se menciona expresamente, y de la que no podía salir sin permiso expreso del relator “... sot pena de bar y traÿdor y de cent liures...”. Para asegurar la dicha obligación no es frecuente en estos procesos privados la práctica de la anotació de bens, solicitada, por otra parte, siempre en las demandas, es más frecuente que se den las fermanças de que habla el fur del Católico de 1488, que estamos comentando, “...e lo pres sia delliurat e donat a bones e sufficients fermançes de presentar aquell tota hora que sia demanat...”. Fernando II, ${ }^{62}$ además, contempló para evitar abusos, que, entre las funciones del abogado fiscal, figurase la de asesorar "...en lo deliurar, e traure los hòmens presos de la presó per crims detenguts...”. De esta forma se da trámite que establece el fur de 1488 “... qui serà pres, dins dos dies après que serà pres, sia denunciat e confessat e la denunciació dexada en poder de l'escrivà..." sobre la exigencia de adoptar rápidamente la resolución de dejar o no al presó en libertad hasta el momento de la sentencia.

Este tema de los presos por razón de procesos sustanciados en la Real Audiencia preocupó a Carlos I que estableció la obligación de llevar, un Llibre dels presos a cargo de los escrivans de manament en el que "....sien continuats los presos e la causa perquè estan pres, e lo que sobre aquells serà delliberat e provehit... se haja de fer menció de tots los que exiran de la presó, perquè 's sapia com són entrats e exits". ${ }^{63}$

En los procesos, en el tiempo de las dilaciones, constan actas de realización de pruebas testificales a petición de las partes, en las que además de su nombre, edad, domicilio y profesión se les pregunta exclusivamente sobre los capítulos de la demanda; o queda insertada acte de desospitacio ${ }^{64}$ realizado por tres desospitadors reals, un médico y dos cirujanos en la persona del nafrat, emitiendo dictamen sobre el estado de las heridas y momento en que lo consideran curado, tras realizar cuantas visitas fuesen necesarias, en este caso a petición del por el procurador del acusado ${ }^{65}$. Pasados los plazos de la dilación, se ordena que las testificales y otras pruebas sean tenidas por publicadas y se inserten en el proceso, y este reste en punt de acord sense altra nova provisió, y que se entregue copia a la parte que lo pida.

62 FRV libro I, rúbrica III, furs XLIV y XLV.

63 ARV, RC, 601 Pragmàtica de la institució de la Real Audiencia feta per la Cesarea Magestat del Emperador Carlos Quinto en Barcelona lo primer de Maig 1543, Cap.7.

64 FRV libro IX, rúbrica XXXII, furs XI

65 ARV, Procesos Criminales II Parte, reg. 207 de 1566.

SCRIPTA, Revista internacional de literatura i cultura medieval i moderna, núm. 13 / juny 2019 / pp. 113 - 138 ISSN: 2340-4841 $\cdot$ doi:10.7203/SCRIPTA.13.15477 
María Dolores Hernández-Fernández. Procesos criminales a instancia de parte privada. Apuntes sobre su praxis en el Real Consell Criminal valenciano en época de Felipe II

Respecto al final del proceso, la Pragmática de la Institución de la Real Audiencia de 1 de mayo de 1543 en el Cap. 5 establecía “...que de totes les causes sia fet original procés per lo escrivà de aquelles...” y que el original no "... haja de exir de mans de l'escriv... mas haja portar aquell conclús en la causa al relator de aquella, perquè al dit original se faça relació, e se vote la causa...". La última anotación que consta en los procesos es la fecha de remisión de la causa al relator, suscrita por el escribano del mandamiento y realizada tras el plazo de dilaciones. Esta parte del proceso estimamos que se realizaba de forma oral y no queda ninguna constancia.

Y una vez ordenada la sentencia por el relator se publica por el escrivà de manament. No se insertan en los procesos las sentencias, aunque, en ocasiones, existe un breve resumen de las mismas en la portada de los procesos ${ }^{66}$, en alguno de los casos hemos constatado el plazo de tres meses como frecuente aunque lo más habitual es que se alargue hasta seis meses. De los procesos estudiados no se encuentran sus sentencias entre conservadas en el Archivo del Reino de Valencia, es una serie muy afectada por los problemas de conservación.

\section{Conclusión.}

El estudio de los procesos criminales sustanciados en primera instancia ante el Real Consell Criminal y conservados en el ARV revela que estos eran cotidianamente avocados a suplica de la parte demandante mediante decreto expedido por el regente de la Real Audiencia en las décadas estudiadas de 1560 y 1570 . Además, los procesos criminales de presencia instados por parte privada revelan que son causas castigadas con las más graves penas corporales y por los que se podía pedir y solicitar por el denunciante el apresamiento del delat, ya que por decisión de Felipe II no podía ser otro el objeto de los procesos criminales sustanciados ante dicho tribunal. Se constata también que en la sustanciación de los mismos se cumple escrupulosamente lo establecido en furs, mostrado la existencia de ordre judiciari, una praxis, con la cual se da un claro sentido a la dispersión normativa foral. Los puntos claves en el proceso criminal, cuando se trata de delitos castigados con las más graves penas corporales y/o con prisión, según regulación por fueros son: la denuncia formal del demandante por medio del denunciació, clam e criminal acusació o libello, la prestació de sagraments, la contestació solemne de pleyts. ${ }^{67}$ En este caso añadiendo además un sistema de plazos para realizar la confesión, establecidos para evitar los abusos y vejaciones que se estaban cometiendo a su calor con ánimo de calumniar y vejar. Se ha podido verificar repetidamente en los procesos estudiados cómo van recogiendo de modo ordenado lo que los sucesivos furs fueron disponiendo para el castigo de crímenes cuyas condenas podían reportar gravísimas penas corporales en caso de que fuesen culpables. Su forma definitiva es una creación prácticamente de Fernando II, que va completando y aclarando los furs antiguos consiguiendo un sistema que respeta al mismo tiempo

66 Existen series en el ARV de la Real Audiencia de sentencias y conclusiones criminales, pero no están completas.

67 FRV, libro I, rúbrica III, furs VII-XI y rúbrica VI, fur V.

SCRIPTA, Revista internacional de literatura i cultura medieval i moderna, núm. 13 / juny 2019 / pp. 113 - 138 ISSN: 2340-4841 $\cdot$ doi:10.7203/SCRIPTA.13.15477 
María Dolores Hernández-Fernández. Procesos criminales a instancia de parte privada. Apuntes sobre su praxis en el Real Consell Criminal valenciano en época de Felipe II

el derecho a la justicia de los denunciantes y de los demandados evitándoles vejaciones. Todo el proceso se articula sobre unos plazos breves para solventar la situación presente o futura de prisión del delat, circunstancia que más preocupa y en torno a la cual gira todo el proceso. Aunque a la hora de dictar sentencia no se cumplen los plazos, el proceso sí cumple la estructura. Un proceso construido mediante el uso preceptivo de unas fórmulas, fermances, y con una concreción de lo que se acusa en la demanda, capítulos, que no se ocultan a la parte demandada y a la que se dan los mismos plazos para presentar las pruebas que estime conveniente en su descargo. Entre las fermances la más importante es el juramento de la pena de talión por el demandante, junto con una escenificación solemne mediante sagraments y bajo pena de bar i traÿdor y caplleuta del inculpado para excarcelado. Un proceso en el que cobra importancia que los inculpados no sean vejados y que en principio debía ser igual en todos aquellos órganos judiciales que conocieran de este tipo de causas con presos. 
María Dolores Hernández-Fernández. Procesos criminales a instancia de parte privada. Apuntes sobre su praxis en el Real Consell Criminal valenciano en época de Felipe II

\section{Bibliografía}

Alonso Romero, M.P. (1982) El Proceso penal en Castilla. Siglos XIII-XVIII, Salamanca, Universidad de Salamanca, pp.3-4 y 97-98.

Alanya, Ll., Aureum opus regalium privilegiorum civitatis et regni Valentie (1515), Valencia, [Índices preparados por Cabanes Pecourt, M.D., Anubar, 1972].

Bernabé Gil, D. (1993) "Una coexistencia conflictiva, municipios realengos y señoríos de su contribución general en la Valencia foral", Revista de historia moderna: Anales de la Universidad de Alicante, 12, (Ejemplar dedicado a: Jurisdicción y señorío en la España Moderna), pp. 11-78.

Bernabé Gil, D. (2010) "Quince años de estudios sobre el régimen señorial valenciano en la Edad Moderna" en Esteban Sarasa Sánchez, E. y Serrano Martín, E (coord..) Estudios sobre señorío y feudalismo: homenaje a Julio Valdeón, pp. 197-234.

Bernabé Gil, D. (2014) "La Lugartenencia y las Subrogaciones locales de la Gobernación General de Orihuela en la Edad Moderna", Revista de historia moderna: Anales de la Universidad de Alicante, 32, pp. 33-60.

Canet Aparisi, T (1986) La Audiencia valenciana en la época foral moderna, Valencia, Ed. Alfons El Magnànim, Institució Valenciana d'Estudis i Investigació.

Canet Aparisi, T (1990) La magistratura valenciana: (S.XVI-XVII), Valencia, Universidad de Valencia, Departamento de Historia Moderna.

Canet Aparisi, T. (2001) "La justicia del emperador, la refundación Carolina de la Audiencia valenciana" en Coord. Rivero Rodríguez, M. y Álvarez-Ossorio Alvariño, A. Carlos V y la quiebra del bumanismo político en Europa (1530-1558), Madrid, Sociedad Estatal para la Conmemoración de los Centenarios de Felipe II y Carlos V, Vol. 2, pp. 173-198.

Canet Aparisi, T. (2002) "Entre la visita y la sucesión. La resistencia a la virreinalización administrativa en Valencia entre Carlos V y Felipe II”, Estudis: Revista de historia moderna, 28, 2002, pp. 205-240.

Canet Aparisi, T. (2006) "Felipe II y la Corona de Aragón bajo el signo del viraje" en coord. Belenguer Cebrià, E. y Garín Llombart, F.V. La Corona de Aragón: siglos XII-XVIII, pp. 209-240.

Canet Aparisi, T. (2010) "Conflictividad jurisdiccional en la Valencia moderna, instancias enfrentadas y vías de solución”, Studia historica. Historia moderna, 32, pp. 335-373.

Ciscar Pallares, E. (2009) La justicia del abad. Justicia señorial y sociedad en el reino de Valencia. (Valldigna, siglos XVI, XVII y XVIII), Valencia, Institució Alfons el Magnànim.

Febrer Romaguera, M.V. (1996) “Orígenes y configuración jurídica del feudalismo foral valenciano", en coord. Prats Albentosa, L. Estudios en homenaje a la profesora Teresa Puente, Vol. 2, Valencia, Universitat de València, pp. 421-456.

Fori regni Valentiae (1547-1548) Pastor, F.J. (Ed.) Valencia, Mey J. (Imp.).

Graullera Sanz, V., (1997) “El proceso penal en la Audiencia foral de Valencia”, en Estudios jurídicos

SCRIPTA, Revista internacional de literatura i cultura medieval i moderna, núm. 13 / juny 2019 / pp. 113 - 138 
María Dolores Hernández-Fernández. Procesos criminales a instancia de parte privada. Apuntes sobre su praxis en el Real Consell Criminal valenciano en época de Felipe II

en memoria del profesor Dr. D. José Ramón Casabó Ruir, Valencia, Universitat de València-Institut de Criminologia, 1 vol., pp. 947-968.

Hassemer, W. y Muñoz Conde, F. (2012) Introducción a la criminología y al derecho penal, Valencia, Tirant lo Blanch, pp. 31-35 y 164-165.

Hernández Ruano, J. (2014) Poderosos pleitos. El señorío de Montesa siglos XVI-XVII, Castellón de la Plana, UJI.

Matheu i Sanz, L. (1704) Tractatus de regimine Regni Valentiae, Lyon.

Mantecón Movellán, T. A. (1996) "Desviación, disciplina social e intervenciones judiciales en el Antiguo Régimen”, en Studia Historica. Historia Moderna, 14, pp.223-243.

Obarrio Moreno, J. A. (1994) "La recepción del ius commune en los furs de Valencia: El proceso penal", en Anales de la Universidad de Alicante. Facultad de Derecho, 9, pp. 39-114.

Piles Ros, L. (1970) Estudio documental sobre el bayle general de Valencia, su autoridad y jurisdicción, Valencia, Institución Alfonso el Magnánimo.

Pérez García, P. (1991) La justicia criminal de Valencia (1479-1707): una magistratura urbana valenciana ante la consolidación del absolutismo, Valencia, Generalitat Valenciana.

Pérez García, P. (2013) "Perspectivas de análisis del proceso penal en el Antiguo Régimen: el procedimiento ordinario de Valencia Foral (ss. XVI y XVII)", en Clio \& Crimen: Revista del Centro de Historia del Crimen de Durango, 10, pp. 35-82.

Peset Reig, M. et alii, (1995) Derecho Foral Valenciano, Valencia, Albatros Ediciones, pp.15-17.

Salvador Esteban, E. (1974) Cortes valencianas del Reinado de Felipe II, Valencia, UV, Departamento de Historia Moderna.

Salvador Esteban, E. (1984) "La Gobernación valenciana durante la Edad Moderna. Cuestiones en tomo a su singular estructura territorial", Studia historica et philologica in honorem M. Batllori. Roma, Instituto de España, pp. 443-455.

Tomas y Valiente, F. (1969) El derecho penal de la Monarquía Absoluta (siglos XVI, XVII y XVIII), Madrid, Tecnos, pp.23-47 y 154-200. 